\title{
PERAYAAN SABAT MENURUT JOHN CALVIN
}

\author{
Rendy Tirtanadi \\ Gereja Kristus Rahmani Indonesia Kelapa Gading
}

\begin{abstract}
ABSTRAK: Ada banyak interpretasi tentang perayaan Sabat, oleh karena itu agar dapat menangkap keseriusan atas perintah untuk menjalankan Sabat ini diperlukan suatu konsep pemahaman yang komprehensif. John Calvin yang dikenal sebagai seorang pemikir yang sistematis dan teolog yang seksama sekaligus praktis patut mendapat perhatian kita. Demi memahami konsep Sabatnya, Calvin menuliskan tema Sabat dalam berbagai tulisannya, baik dalam tafsiran, Institutes, katekismus, dan khotbah-nya. Dengan demikian, kita akan memperoleh suatu konsep Sabat yang Alkitabiah dari kitab Perjanjian Lama dan Baru, tanpa harus berkompromi dengan konteks zaman saat Calvin hidup.
\end{abstract}

KATA KUNCI: John Calvin, sabat, prinsip satu di dalam tujuh, sakramen, dekalog, istirahat rohani, Anak Manusia, hari Tuhan.

ABSTRACT: There are many interpretations about the Sabbath observance, therefore in order to grasp the seriousness of this commandment, the comprehensive understanding of the Sabbath concept is truly required. John Calvin who is famous for his sistematic and careful thought is worthy to be observed on this issue. To comprehend his Sabbath concept, Calvin wrote many articles about Sabbath, from his commentaries, Institutes, Catechisms, 
and preaching. Finally, we can understand the biblical Sabbath concept, starting from the Old to the New Testament, without compromising with the context of Calvin's life.

KEYWORDS: John Calvin, Sabbath, one day in seven principle, sacrament, decalog, spiritual rest, Son of Man, the Lord's day.

\section{Pendahuluan}

Kata Sabat pertama kali muncul dalam Alkitab, sebagai bagian dari Dekalog di dalam Keluaran 20:11. ${ }^{1}$ Definisi Sabat menurut Pictorial Encyclopedia of the Bible: "Sabbath, in origin the closing day of a seven day week. Conforming to ancient tradition, Judaism has always observed the sabbath upon the seventh day of the week, Saturday."2 Kata benda Sabat, berasal dari kata kerja bahasa Ibrani (הַּש terminate, to be at an end, dalam perkembangannya, kata kerja dari Sabat ini berarti to be inactive, to rest. ${ }^{3}$ Gambaran tentang Sabat sebenarnya telah ada sejak penciptaan, yaitu dalam kitab Kejadian 2:2-3, yaitu pada saat Allah selesai dengan karya penciptaan dan beristirahat pada hari ketujuh dan menguduskannya, namun demikian kata Sabbath tidak digunakan dalam ayat ini. ${ }^{4}$

1 Pictorial Encyclopedia of the Bible, Merryl C. Tenney.Ed.(Grand Rapids: Zondervan, 1976),s.v. "sabbath."

2 The Interpreter's Dictionary of the Bible, George Arthur Buttrick.Dictionary ed. (New York: Abingdon Press, 1962), s.v. "sabbath."

3 Ibid.

4 Pictorial Encyclopedia of the Bible, s.v. "sabbath." 
Jika memperhatikan Dekalog yang ada, hanyalah hukum keempat, yaitu mengenai hukum Sabat inilah yang paling banyak diperdebatkan. ${ }^{5}$ Banyak orang memandang Sabat sebagai pelanggaran atas kebebasan pribadi mereka satu hari yang telah Allah rebut dari mereka, dan bukan sebagai hari yang Allah berikan kepada mereka untuk beristirahat, menyembah dan suatu perayaan. ${ }^{6}$ Di sini terdapat banyak perbedaan interpretasi tentang perayaan Sabat. Untuk itu dibutuhkan suatu pemahaman konsep Sabat yang komprehensif, terintegrasi, dan dapat dipertanggungjawabkan.

Alasan penulis memilih Calvin untuk dikaji pemikirannya mengenai Sabat, karena: Pertama, Calvin memberikan deskripsi konsep Sabat secara komprehensif, mulai dari tafsiran-tafsiran Sabat dalam kitab Perjanjian Lama (Sabat Yahudi), ke kitab Perjanjian Baru (Sabat Kristen), khotbahkhotbah Calvin, katekismus, serta melalui tulisan-tulisannya dalam Institutes. Kedua, Calvin menekankan perintah Sabat sebagai suatu perintah yang serius, seperti yang tertulis dalam Alkitab, bahwa Allah memberikan teguran yang keras yaitu berupa hukuman mati bagi pelanggar Sabat, ${ }^{7}$ dan sekaligus penghargaanNya akan ketaatan Sabat. Penekanan akan Sabat, Calvin nyatakan dalam Institutes sebagai berikut:

The Lord enjoined obedience to almost no other commandment as severely as to this. When he wills through the prophets to indicate that all religion has been overturned, he complains that his Sabbaths have been polluted, violated, not kept, not hallowed as if, with this homage omitted, nothing more remained in which he could be honored.

5 J. Douma, The Ten Commandments, Manual to the Christian life (Phillipsburg: P\&R, 1996), 110.

6 Bruce A. Ray, Celebrating the Sabbath (Phillipsburg: P\&R, 2000), 4-5.

7 Lihat Kel. 31:14. 
He bestows highest approbation upon its observance. ${ }^{8}$

Dalam artikel ini, penulis berusaha mendeskripsikan beberapa keunikan konsep Sabat dari pemikiran John Calvin (1509-1564) yang signifikan untuk dikaji, menguraikan beberapa tanggapan dari beberapa sarjana ahli Calvin, serta memberikan analisa yang diperlukan. Pembahasan Sabat tersebut meliputi one day in seven principle, Sabat dalam Dekalog, spiritual rest, Sabat sebagai sakramen, Sabat Anak Manusia, Hari Tuhan, dan Sabat eskatologis.

\section{Konsep Sabat dalam Perjanjian Lama}

Prinsip "One day in Seven"

Pertanyaan yang sering muncul di seputar waktu pelaksanaan Sabat adalah apakah gereja patut mewajibkan umat Allah untuk beribadah pada satu hari tertentu ataukah jemaat bebas untuk menentukan pilihan hari Sabat masing-masing? Dalam tafsirannya di Kitab Kejadian 2:2-3, Calvin tidak menentukan pilihan atas hari tertentu untuk merayakan Sabat. Calvin menekankan "one day in seven principle". ${ }^{9}$ Dengan demikian bisa timbul dua kemungkinan penafsiran. Pertama, "every seventh day" bisa dipahami sebagai hari ketujuh atau kemungkinan kedua, "every seventh day" adalah satu hari dalam satu minggu yang ditetapkan sebagai hari Sabat, tanpa mengkhususkan satu hari tertentu. Selain itu, sulit menentukan signifikansi dari angka tujuh yang dijelaskan Calvin, apakah menunjuk kepada suatu

\footnotetext{
8 Calvin, Institutes, 2.8.29., bdk. Bil.15:32-36; Kel.31:13 ; 35:2; Yeh. 20:12-13; 22:8; $23: 38$.

9 John Calvin, Commentaries on the First Book of Moses, called Genesis, terj. John King (Grand Rapids: Baker, 1993), 105.
} 
keabadian Sabat atau ketidak sempurnaan Sabat, atau keduanya merupakan kemungkinan yang bisa diambil. Alternatif manakah yang sesungguhnya merupakan pilihan Calvin, tidak diungkapkannya. Dalam tafsiran Calvin pada Kitab Kejadian, ia mengatakan bahwa Allah telah menyatakan hari ketujuh sebagai hari yang dikhususkan untuk beribadah, namun berbeda dengan eksposisinya dalam Institutes, Calvin menjelaskan bahwa hari yang dikuduskan itu, tidaklah harus jatuh pada hari ketujuh. Dalam Institutes Calvin hanya mengatakan a stated day dan a day of rest. Di sini, Calvin bisa saja hendak mengatakan bahwa hari apa yang ditentukan oleh orang-orang Kristen pada waktu itu bersifat netral/ bebas untuk memilih hari ibadah bagi mereka. Richard B. Gaffin, mengatakan bahwa terdapat kontradiksi antara Institutes dan tafsiran Calvin di kitab Kejadian. ${ }^{10}$

Kata rest sendiri dalam kamus Webster memiliki 30 macam definisi yang berbeda, yang secara umum mengandung pengertian yang serupa yaitu istirahat dari berbagai kegiatan untuk mendapatkan kesegaran kembali, baik secara jasmani maupun rohani, yang bisa ditempuh dengan berbagai cara. ${ }^{11}$ Oleh karena itu penulis berpendapat pemahaman "rest"

10 Richard B. Gaffin, Calvin and the Sabbath (Fearn: Mentor, 1998), 75.

11 Webster College Dictionary, mendefinisikan kata benda rest sebagai: 1 . The refreshing quiet or repose of sleep 2. Refreshing ease 3. Relief or freedom esp. From trouble, anxiety, etc 4. A periode or interval of inactivity, repose, solitude, or tranquillity 5. Mental or spiritual calm 6. The repose of death: eternal rest 7. Cessation or absence of motion 8. Music: $a$. An interval of silence between tones $b$. A mark of sign indicating it 9.Short pause within a line; caesura 10.Any stopping or resting place 11. A piece or device bywhich something is supported or upon which it can rest 12.To refresh oneself as by sleeping, lying down or relaxing 13. To be at ease; have tranquillty or peace 14. To repose in death 15 . To cease from motion or activity; stop 16. To remain with our further action or notice: to let a matter rest 17 . To lie, sit, lean or be set: his arm rested on the table 18. (of land) to lie fallow or unworked 19. To be imposed as a burden or resposibility (usu. fol. by on or upon) 20. To rely (usu. fo. by on or upon) 21. To be based or founded (usu. fol. by on or upon) 22. To be found belong; reside (often fol. by with): the blame rest with them 23. To be fixed or directed on something, as the eyes or a gaze 24. Law. To conclude the 
yang dikemukakan Calvin pun semestinya tidak bisa diartikan secara sempit hanya sebagai "istirahat" yang berarti berhenti dari bekerja saja. Untuk penjelasan hari ketujuh ini, mengapa Allah menentukan Sabat pada hari ketujuh, dan bukan pada hari keenam atau kesepuluh tidak menjadi pembahasan Calvin. Bagi Calvin, Alkitab memang sering melambangkan angka tujuh, sebagai lambang kesempurnaan mau mengingatkan bahwa orang percaya harus berjuang untuk suatu kesucian yang sempurna ${ }^{12}$ yang hanya dapat diperolehnya dari Allah saja, dan bukan berasal dari diri mereka. Calvin menjelaskan mengenai signifikansi angka tujuh tersebut dengan dua tafsiran yang mungkin. Pertama, menunjuk kepada keabadian perpetuity (Kejadian 2:2-3), mengaitkan relasi antara hukum keempat dengan istirahat Allah saat selesainya penciptaan. Dan kemungkinan kedua, angka tujuh menunjukkan bahwa Sabat tidak akan sempurna sampai tibanya Sabat yang sempurna pada the eschatological Last Day. ${ }^{13}$ Namun demikian, Calvin pun tidak berkeberatan bila ada pihak lain yang memandang ringan signifikansi angka tujuh ini, karena yang terpenting adalah Allah memang telah menetapkan satu hari di bawah pengawasan hukum bagi umatNya

introductions on evidence in a case 25.To give rest to; refresh with rest. 26. To lay or place for rest, ease, or support: to rest one's back against a tree 27. To direct or cast; to rest one's eyes on someone. 28. To base or let depend as on some ground of reliance 29. To bring to rest, halt, stop 30. Law. To conclude the introduction of evidence on: to rest one's case.

12 Calvin, Institutes of the Christian Religion, Ed.John T. McNeill (Philadelphia: WJK,1960), 2.8.28-30. Kesucian yang sempurna dimaksudkan adalah melalui perenungan akan Sabat di sepanjang kehidupan, dan bukan hanya pada satu hari dalam seminggu saja. Seperti yang dijelaskan dalam kalimat Calvin berikut ini: "It would seem, therefore, that the Lord through the seventh day has sketched for his people the coming perfection of his Sabbath in the Last Day, to make them aspire to this perfection by unceasing meditation upon the Sabbath throughout life."

13 Ibid., 2.8.30. 
untuk melatih diri beribadah demi suatu istirahat rohani, ${ }^{14}$ dan menyembah Allah dalam suatu holy occupation baik secara pribadi maupun bersamasama. Untuk memperjelas maksud Calvin ini, bisa memperhatikan penegasannya berikut ini:

There is indeed no moment which should be allowed to pass in which we are not attentive to the consideration of the wisdom, power, goodness and justice of God in His admirable creation and government of the world; but since our minds are fickle, and apt therefore to be forgetful or distracted, God in His indulgence providing against our infirmities, separates one day from the rest, and commands that it should be free from earthly business and cares, so that nothing may stand in the way of that holy occupation..$^{15}$

Berbeda dengan Calvin, John Murray menanggapi bahwa pemisahan satu hari dalam tujuh hari itu pasti mempunyai signifikansi tertentu, yaitu demi tercapainya suatu kesucian dan memberikan manfaat bagi orang percaya, Murray mengatakan:

It needs to be underlined that Sabbath observance soon becomes obsolete if it does not spring from the sense of sanctity generated and nourished in us by the recognition that God has set apart one day in seven. ${ }^{16}$

Selain itu Murray berpendapat ${ }^{17}$ bahwa keberlangsungan perintah Sabat merupakan creation ordinance, peraturan ciptaanAllah sejak penciptaan (Kejadian 2:2-3). Sabat ini tidak berkaitan dengan dosa dan penebusan manusia, oleh karena itu dosa tidak membatalkan creation ordinance, dan di

\footnotetext{
14 Ibid., 2.8.31.

15 John Calvin, Commentaries on the Four Last Books of Moses (Exodus to Deuteronomy), terj. Charles William Bingham (Grand Rapids: Baker, 1993), 437.

16 John Murray, Collected Writing of John Murray (Edinburgh: The Banner of Truth Trust, 1976), 210.

17 Ibid., 206-216.
} 
sini istirahat Sabat dimaknai sebagai teladan Ilahi. Dengan demikian Murray menyimpulkan bahwa pola/ urutan manusia bekerja selama enam hari dan istirahat satu hari adalah mengikuti skema agung dari karya penciptaan Allah, dan hari Minggu sebagai Sabat Kristen.

Herman Witsius (1636-1708) menekankan hal berbeda dengan Calvin mengenai hari ketujuh ini, bagi Witsius ketika Allah memberkati hari ketujuh bisa berarti dua hal. Pertama, Allah memiliki suatu kesenanganNya sendiri untuk menikmatinya. Bahkan merupakan hari yang penuh sukacita bagi para malaikat dan manusia, ketika dosa belum masuk. Kedua, itu juga merupakan berkat bagi hari ini, yaitu bagi manusia yang meneladani Allah, juga dapat menikmati berkat melimpah dan dianggap sebagai berkat awal atas istirahat yang paling penuh bahagia di sorga nanti. ${ }^{18}$

Hampir enam dekade setelah meninggalnya Calvin, Thomas Watson (c.1620-1686) seorang Puritan menegaskan pandangan Calvin bahwa menyisihkan satu hari khusus sebagai hari Sabat bagi Allah adalah sesuatu yang penting, lalu Watson memberikan dua kepentingan dari Sabat. Pertama, demi kepentingan Allah. Melalui hari Sabat, Allah dikenal sebagai Allah yang berdaulat atas manusia, dan berkuasa untuk memerintah manusia agar memberikan satu hari untuk beribadah kepadaNya. Dan kedua, demi kepentingan manusia. Karena melalui Sabat, maka manusia bertumbuh dalam kesucian. Enam hari bekerja bisa saja membuat manusia melupakan Allah, dan pada hari Sabat, membawa manusia kembali

18 Herman Witsius, The Economy of the Covenants between God and men (Phillipsburg: P\&R, 1990), 120. 
mengingat Allah. ${ }^{19}$ Watson dalam bukunya The Ten Commandments menyetujui untuk hari Sabat Kristen dilakukan pada hari pertama dari suatu minggu, menggantikan Sabat Yahudi pada hari ketujuh. Walaupun Watson setuju dengan konsep Calvin mengenai "one day in seven", namun Watson lebih jauh menyimpulkan bahwa moralitas atau substansi bukan terletak persis pada hari ketujuh. Watson menyetujui Agustinus dan Athanasius berargumentasi bahwa Kristus bangkit pada hari pertama dari suatu minggu dan menampakkan diri sebanyak 2 kali kepada para muridNya, tujuannya adalah untuk memberi isyarat bahwa Ia memindahkan hari Sabat Yahudi ke Hari Tuhan, atau hari Minggu, seperti yang dikatakan Agustinus dan Athanasius. ${ }^{20}$

Sementara itu J. Douma, seorang guru besar Etika dan pendeta dari gereja-gereja Reformed yang ada di Belanda tidak sependapat dengan Calvin perihal "one day in seven principle" ini. Keberatan Douma ${ }^{21}$ yang pertama terletak pada argumentasi Calvin yang menyatakan bahwa penetapan satu hari dalam satu minggu adalah karena untuk mengatasi faktor "kelemahan" manusia yang tidak bisa memberikan enam harinya kepada Allah, dipandang oleh Douma tidak memiliki pembuktian yang kuat. Khususnya dalam perspektif pengharapan eskatologis, yaitu ketika kita merayakan Sabat yang tanpa "kelemahan" dan dosa di Surga kelak, bukankah kelak kita merayakan Sabat setiap hari? Kedua, enam hari bekerja seharusnya juga sebagai pelayanan kepada Allah dan hari Sabat bukan satu-

19 Thomas Watson, The Ten Commandments (Pennsylvania: The Banner of Truth Trust, 1959), 94.

20 Ibid., 95. Bdk. Yoh 20:19-26.

21 J. Douma, The Ten Commandments, Manual to the Christian Life (Phillipsburg: P\&R, 1996), 124. 
satunya sebagai hari puncak di mana manusia bisa berkomunikasi dengan Allah. Douma menyimpulkan bahwa setiap hari memiliki kepenuhannya masing-masing, perbedaan antara hari-hari yang ada bukan karena kelemahan dosa manusia, melainkan karena berasal dari sebuah ciptaan yang dirancang oleh Allah sendiri..$^{22}$

Meresponi "one day in seven principle" ini, Karl Barth yang dipandang sebagai teolog yang setara dengan teolog-teolog masyhur seperti Agustinus, Thomas Aquinas, Luther dan Calvin, ${ }^{23}$ perlu mendapatkan perhatian. Bagi Barth memahami Sabat harus melihat aspek relasi manusia dengan Allah, oleh karena itu harus memperhatikan akan adanya klaim bahwa Allah menghendaki bukan hanya keseluruhan waktu manusia, namun juga waktu khususnya, bukan hanya seluruh kegiatannya, namun juga kegiatan khusus bagiNya. Barth berpendapat bahwa manusia tidak dapat memahami hari kudus tanpa terlebih dulu memahami hari kerja, dan demikian pula sebaliknya. ${ }^{24}$ Penulis menilai bahwa Barth enggan membuat distingsi antara hari Sabat dengan enam hari lainnya, karena keduanya saling terkait, dapat dibedakan namun tidak dapat dipisahkan. Mengenai penjelasan Calvin untuk tidak membangun signifikasi angka 7 (tujuh) sebagai angka yang menunjuk kepada kesempurnaan, dianggap Barth sebagai suatu nasehat yang baik.

\footnotetext{
22 Ibid., 125.

23 Karl Barth, Theologian of Freedom, ed., Clifford Green (Minneapolis: Fortress Press, 1991), 12. Selain itu Barth juga sebagai seorang asisten pendeta di sebuah gereja German Reformed di Jenewa pada tahun 1909 serta melayani sebagai pendeta di gereja Safenwill selama 10 tahun dari tahun 1911 sampai tahun 1921.

24 Ibid., 57.
} 
R.C. Sproul mengomentari interpretasi Calvin dengan mengatakan bahwa memang ada banyak perdebatan mengenai pelaksanaan Sabat yang tepat. Namun Sproul meringkaskan kesimpulannya dengan mengatakan bahwa Sabat berarti "ketujuh", yang menunjuk kepada sebuah siklus dari satu hari dalam tujuh, dan telah dimulai sejak penciptaan dan masih diberlakukan sampai kini. ${ }^{25}$

Bagi Stephen Tong, Sabat harus dimaknai bukan pada penekanan harinya melainkan pada makna Sabat itu sendiri. Stephen Tong mengatakan:

Maka, di sini penekanannya bukan pada 'hari', tetapi justru pada 'Sabat'. Hari hanyalah wadah di mana kita menikmati istirahat sejati. Sabat yang penting, hari adalah wadahnya. Ketika manusia mementingkan 'hari'-nya dan melupakan 'Sabat'-nya, Tuhan akan marah. Tuhan memberi perintah, "Ingat dan kuduskan hari Sabat." Alasan Tuhan adalah engkau sudah bekerja enam hari lamanya, maka hari ketujuh adalah Sabat Tuhan. Hari ini adalah hari milik Allah. Dari tujuh hari yang Allah berikan kepada manusia, ada satu hari yang harus dikembalikan kepada Tuhan, itulah Sabat Tuhan. ${ }^{26}$

Penulis memandang bahwa prinsip "one day in seven" Calvin kemungkinan berkaitan dengan konteks pembaca Calvin yang sedang menghadapi kelompok yang berbeda, baik kelompok Anabaptis maupun Roma Katolik pada waktu itu. ${ }^{27}$ Di sini penulis berpendapat bahwa

\footnotetext{
25 R.C. Sproul, Essential Truth of the Christian Faith (Illinois: Tyndale, 1992), 240.

26 Stephen Tong, Sepuluh Hukum-Hukum Keempat. Diakses pada tanggal 28 Oktober 2014 di dalam laman http://www.buletinpillar.org/transkrip/sepuluh-hukum-hukum-keempat

27 Lihat uraian Gaffin, Calvin and the Sabbath, 25. Mengutip uraian Louis Praamsma, Calvijn overde Sabbath, "Church and Nation,6 (Nov. 28, 1961):91-92, Praamsma mengatakan bahwa dalam pemahaman Calvin tentang Sabat tidak ada pertentangan baik dalam Commentary kitab Kejadian maupun di Institutes. Hal itu lebih disebabkan pada kemampuan apologetika Calvin yang hidup. Dalam Institutes perhatiannya adalah diarahkan kepada pemerintahan Romawi pada waktu itu yang menekankan pada observasi hari-hari legalistik. Di sisi lain yaitu di dalam
} 
sesungguhnya Calvin tidak ingin terjebak kepada pandangan ekstrim yang tidak memiliki dasar Alkitab yang kuat, sehingga Calvin tidak memberikan ketetapan tentang hari apa yang dipakai untuk merayakan Sabat. Calvin lebih mementingkan makna "Sabat" dari pada persoalan "hari".

\section{Sabat dalam Dekalog}

Mengapa Sabat ditempatkan dalam Dekalog? Clyde Jones ketika membahas Institutes tentang hukum Taurat dan Roh Kristus, mengatakan bahwa ketika Calvin menempatkan dekalog, ia mengaitkannya dengan sejarah penebusan Kristus, dan mampu mengartikulasikan relasi antara dekalog dengan tema doktrin keselamatan. Dengan demikian mempersiapkan pemahaman yang berikutnya yaitu tentang hubungan hukum moral dan berdiamnya Roh Kristus. ${ }^{28}$ Calvin memaknai Sabat dalam Dekalog ini, sebagai: Pertama, Sabat adalah simbol dari"spiritual substance" dan menjadi keunikan bagi Israel dibandingkan dengan bangsa-bangsa lain. Sabat bangsa Yahudi ini menjadi lambang bagi istirahat rohani. Kedua, penekanan Sabat dalam Dekalog ada pada pelaksanaannya, yaitu untuk melatih umat Israel dalam beribadah kepada Allah, ${ }^{29}$ dengan cara berhenti dari segala pekerjaan mereka, mati bagi diri sendiri dan dunia, dan

tafsiran kitab Kejadian, Calvin sedang mengarahkan pandangannya kepada kelompok Anabaptis yang menolak bahwa kitab suci mengajarkan observasi hari Sabat, dan bahkan boleh bekerja pada hari Minggu. Sementara Roma Katolik memandang bahwa hari Minggu sebagai hari Sabat, dan cenderung mensakralkannya.

28 David W. Hall dan Peter A. Lillback, ed., Penuntun ke dalam Teologi Institutes Calvin (Surabaya: Momentum, 2009), 346. Pada bagian ini, Calvin menjelaskan bahwa dasar teks Alkitabnya adalah diambil dari Roma 10:4 "Sebab Kristus adalah kegenapan hukum Taurat, sehingga kebenaran diperoleh tiap-tiap orang yang percaya."

29 Calvin, Commentaries on the Four Last Books of Moses, 433. 
membawa diri seutuhnya kepada Allah. Ketiga, Dekalog sebagai janji dan sekaligus peringatan. Sebagai janji, untuk menunjukkan sukacita Allah ketika manusia menaati hukum-hukumNya, dan sebagai peringatan untuk menunjukkan bahwa Allah membenci ketidakbenaran, dan memperingatkan kita atas perbuatan jahat umatNya. ${ }^{30}$ Perintah Sabat dalam Dekalog adalah juga sebagai janji yang merupakan bayang-bayang akan istirahat rohani/ spiritual rest foreshadowed. ${ }^{31}$ Elemen simbol dalam hukum Allah ini berhenti, namun bentuk baru dari perjanjian itu berlanjut dengan realitas dan substansi Sabat yang sesungguhnya yaitu dengan kedatangan Kristus. Penegasan Calvin di sini adalah bukan persoalan frekuensi perayaan Sabat sebagai "external observance", melainkan lebih kepada "sacred observance" yaitu persoalan istirahat rohani dan menghasilkan buah pengalaman rohani melalui perenungan pribadi dan ibadah bersama. ${ }^{32}$ Keempat, untuk menunjukkan keseriusanNya, maka Allah menuliskan perintah Sabat ini ke dalam hukum keempat dari Dekalog, dan terungkap melalui tulisan Calvin berikut ini:

That the keeping of Sabbath was a serious matter, since God inculcates no other commandment more frequently, nor more strickly requires obedience to any; and a gain, when He complains that He is despised, and that the Jews has fallen into extreme ungodliness, He simply says that His "Sabbaths are polluted," as if religion principally consisted in their observance. ${ }^{33}$

30 Ford Lewis Battles, Analysis of the Institutes of the Christian Religion of John Calvin

(Phillipsburg: P\&R, 2001), 121. Bdk. Institutes, 2.8.4.

31 Ibid., 127. Bdk. Calvin, Institutes, 2.8.29.

32 Calvin, Institutes, 2.8.34.

33 Calvin, Commentaries on the Four Last Books of Moses, 435. 
Dari pembahasan di atas, penulis memberikan dua poin penting yang harus digaris bawahi. Pertama, Calvin hendak menyampaikan bahwa di dalam Kristus, maka janji akan perintah Sabat dalam Dekalog ini telah tergenapi. Kedatangan Kristus menghapuskan bagian seremonial dari perintah ini. Kedua, Calvin menegaskan bahwa orang-orang Kristen mulamula mengubah hari Sabat Yahudi ke hari kebangkitan Tuhan untuk menandai bahwa bayang-bayang Sabat telah berhenti. ${ }^{34}$

Murray lebih mempertajam pandangan Calvin, dengan mengatakan bahwa kewajiban untuk menjalankan Sabat bukan karena kedudukan perintah Sabat ini ada di bawah pengaturan Dekalog, melainkan karena Sabat memang telah dimulai sejak penciptaan, agar menjadi teladan Ilahi, karena Allah berhenti pada hari Sabat dan menguduskannya. ${ }^{35}$ Selain itu Tuhan Yesus pun mengakui relevansi pelaksanaannya, walau Yesus sendiri mengoreksinya dengan berkata bahwa Sabat dibuat untuk manusia, dan bukan manusia untuk Sabat. ${ }^{36}$ Namun, perbedaan pelaksanaan Sabat antara yang ada di Dekalog dengan yang ada dalam Perjanjian Baru, bukan karena adanya diskontinusitas. ${ }^{37}$ Murray mengingatkan bahwa setiap perintah dalam Dekalog mengandung kesuciannya tersendiri, ${ }^{38}$ dan Sabat tentunya termasuk salah satu perintah yang dimaksudkan Murray.

\footnotetext{
34 Battles, Analysis of the Institutes, 128-129.

35 Keluaran 20:11.

36 Murray, Collected Writings, 206-208.

37 Ibid., 211.

38 Ibid., 215. Murray menggarisbawahi bahwa setiap perintah mempunyai kesuciannya masing-masing. Perintah pertama, adalah kesucian akan keberadaan Allah. Perintah kedua, adalah kesucian akan penyembahan kepada Allah. Perintah ketiga, adalah kesucian akan nama Allah. Perintah kelima, adalah kesucian akan relasi dengan orang tua. Perintah keenam, adalah
} 
Watson sependapat dengan Calvin dalam hal pentingnya aspek mengingat. ${ }^{39}$ Watson mengatakan bahwa perintah Sabat yang ada dalam Dekalog, dimaksudkan agar bangsa Israel mengingat akan kekudusan hari Sabat. Implikasi dari pentingnya mengingat, dijabarkan oleh Watson sebagai: Pertama, perintah Sabat ini adalah suatu perintah yang serius. Kedua, pengudusan Sabat adalah demi istirahat dari pekerjaan dan melaksanakan kewajiban ibadah dengan seksama. Ketiga, perintah Sabat adalah perintah yang rasional, karena Allah hanya mengambil satu hari dan memberikan enam hari kepada manusia untuk mengerjakan semua urusannya. Keempat, perintah Sabat menunjukkan suatu keadilan, sebagai hak Allah atas satu hari itu, sehingga mereka yang merebut hari itu dipandang sebagai mencuri dari mahkota sorga. Watson menegaskan bahwa perintah Sabat tidak dibatalkan karena memang itu adalah murni sebagai hukum moral, dan terus berlanjut sampai berakhirnya dunia ini.

The thing I would have you now observe is, that the commandment of keeping the Sabbath was not abrogated with the ceremonial law, but is purely moral, and the observation of it is to be continued to the end of the world. Where can it be shown that God has given us a discharge from keeping one day in seven ${ }^{40}$

Penulis memandang, Murray maupun Watson sepakat bahwa tidak adanya bukti diskontinuitas bagi pelaksanaan Sabat Dekalog, menunjukkan keseriusan Allah agar umatNya tetap menjalankan Sabat. Namun bukan

kesucian akan kehidupan. Perintah ketujuh, adalah kesucian akan sumber kehidupan. Perintah kedelapan, adalah kesucian akan properti/ kepemilikan. Perintah kesembilan adalah kesucian akan kebenaran. Dan perintah kesepuluh adalah kesucian akan kepemilikan pribadi. Khusus untuk kesucian atas perintah keempat atau atas hari Sabat, Murray mengatakan bahwa perintah keempat adalah kesucian atas hari ketujuh.

39 Watson, The Ten Commandments, 93-94.

40 Ibid., 94. 
dari aspek seremonialnya melainkan aspek moralnya, serta memandang Kristus sebagai penggenapan bayang-bayang Sabat, sejalan dengan penegasan Calvin berikut:

But there is no doubt that by the Lord Christ's coming the ceremonial part of this commandment was abolished. For he himself is the truth, with whose presence all figures vanish; he is the body, at whose appearance the shadows are left behind. He is, I say, the true fulfillment of the Sabbath... Christians ought therefore to shun completely the superstitious observance of days. ${ }^{41}$

\section{Spiritual Rest vs Sabat Seremonial}

Tafsiran Calvin tentang Konsep Sabat yang terdapat di kitab Yesaya, merupakan salah satu bagian yang banyak dikutip dalam berbagai diskusi Sabat. Oleh karena itu tafsiran Calvin ini tentu layak untuk dicermati. Calvin memulainya dengan menyinggung tentang karakter Sabat Yahudi seperti apa yang seharusnya menjadi model Sabat yang Tuhan kehendaki. ${ }^{42}$ Pada Yesaya 58:13, istilah menginjak-injak hukum Sabat lebih dimaksudkan kepada cara hidup seseorang, dan bukan pelanggaran Sabat karena melakukan suatu perjalanan tertentu. Hal ini dapat diperhatikan perkataan yang mencerminkan tingkah laku manusia, dalam kata-kata going, atau walking. ${ }^{43}$ Selain itu Sabat sebatas hanya seremonial saja juga menjadi salah satu teguran Allah kepada Israel, melalui nabi Amos ${ }^{44}$ dan Hosea, yang menjalankan Sabat namun sesungguhnya hanya external form religion saja. ${ }^{45}$

\footnotetext{
41 Calvin, Institutes, 2.8.31.

42 Gaffin, Calvin and the Sabbath, 90. Bdk Yesaya 58:13-14; 66:23

43 John Calvin, Commentary on the Book of the Prophet Isaiah, terj. William Pringle, Vol.4 (Grand Rapids: Baker, 1993), 241.

44 John Calvin, Commentaries on the Twelve Minor Prophet Vol I, terj. Rev. John Owen (Grand Rapids: Baker, 1993), 365. Dalam tafsiran Amos 8:5, Calvin menekankan bahwa muncul
} 
Mengenai aktifitas di hari Sabat, Calvin menguraikan Sabat sejati bukanlah bermalas-malasan seharian pada setiap minggu tanpa melakukan kegiatan apa-apa, melainkan harus dimanifestasikan dalam bentuk penyangkalan diri dan dari semua keinginan daging serta pikiran yang jahat. Calvin masuk dalam pemahaman bahwa Sabat yang bersifat seremonial memang telah dihapuskan, namun kebenaran dari Sabat itu tetap berlanjut, karena kematian dan kebangkitan Kristuslah maka orang percaya tetap merayakan Sabat, yaitu dengan meninggalkan pekerjaanpekerjaannya, sehingga Roh Allah dapat bekerja dengan penuh kuasa di dalam diri orang percaya itu. Calvin juga mengingatkan bahwa jika Sabat yang benar dilakukan maka orang Kristen akan menjadi kesukaan bagi Allah, dan sebaliknya Allah juga akan menjadi kesukaannya.

On the contrary, he commanded the Jews to renounce the desires of the flesh, to give up their sinful inclinations, and to yield obedience to him; as no man can meditate on the heavenly life, unless he be dead to the world and to himself. Now although that ceremony has been abolished, nevertheless the truth remains; because Christ died and rose again, so that we have the continual sabbath; that is we are released from our works, that the Spirit of God may work mightily in us. ${ }^{46}$

Calvin mungkin dipengaruhi Luther ketika berbicara tentang spiritual rest. Dalam "Treatise on Good Works", Luther berpendapat sebagai berikut:

The spiritual rest which God especially intends in this commandment (the covenant command to keep the Sabbath holy) is that we not only cease from our labor and trade

ketamakan di antara orang Israel, yang berhitung waktu dengan Allah dan merasa rugi karena tidak dapat melakukan usaha perdagangan mereka di satu hari (Sabat).

45 John Calvin, Commentaries on the Book of the Prophet Daniel to Hosea Volume II, terj. Rev. Thomas Myers, M.A. (Grand Rapids: Baker, 1993), 97.

46 Calvin, the Prophet Isaiah, 438. 
but much more that we let God alone work in us and that in all our powers we do nothing of our own. ${ }^{47}$

Selain itu Luther juga mengatakan bahwa keberadaan manusia sudah rusak oleh dosa dan perlu menyalibkan natur manusia yang berdosa itu di dalam Kristus (Galatia 5:24), sehingga Allah dapat bekerja di dalam diri kita dengan kebaikanNya, "that our work cease and that God alone works in us as we rest." 48 Pada bagian akhir kitab Yesaya pasal 66:23, Calvin mengontraskan dua perbedaan yang terdapat antara Sabat Yahudi dan Sabat Kristen, sebagai berikut: Pertama, Sabat Perjanjian Lama berada dibawah pemerintahan hukum Taurat dan Sabat Perjanjian Baru berada di bawah pemerintahan Kristus. ${ }^{49}$ Dengan demikian berbagai kegiatan yang bersifat seremonial, seperti yang di lakukan oleh para papist Roma Katolik, tidak beda dengan Yudaisme. Kedua, ayat-ayat ini membuktikan bahwa berbagai korban persembahan yang bersifat seremonial dalam hukum Sabat telah dihapuskan, dan digantikan dengan korban yang bersifat rohani dalam pengorbanan Kristus, sehingga kita bisa menghormati dan menyembah Allah dengan tulus dan murni.

Marva J. Dawn dalam "Keeping the Sabbath Wholly" juga mendukung Calvin bahwa manusia membutuhkan Firman Allah dalam spiritual rest dalam Sabat. Bagi orang Yahudi, Taurat ${ }^{50}$ menjadi fokus mereka ketika

47 Dawn, Keeping the Sabbath Wholly, 56. Dikutip dari Luther, Treatise on Good Works, in the Christian in Society I, terj. W.A. Lambert, dan rev. James Atkinson, vol. 44 of Luther's Works, ed., Helmut T.Lehmann (Philadelphia: Fortress, 1966), 72.

48 Ibid, 72.

49 Calvin, the Prophet Isaiah, 438.

50 Marva Dawn menerangkan bahwa kata Ibrani untuk taurat sering diartikan dengan kata "hukum", namun sesungguhnya kata yang lebih tepat sesuai dengan maksud Taurat diberikan 
menjalankan Sabat, sementara bagi orang Kristen Alkitab, sebagai Firman Allah harus mengajar kita akan kasih Allah baik pada saat pembacaan dan perenungan pribadi maupun dalam mendengarkan khotbah pada ibadah bersama. Dengan sarana yaitu Firman Allah, maka kita dapat mengubah pikiran dan jiwa kita disesuaikan dengan perkara sorgawi dan menyingkirkan pekerjaan sehari-hari kita, supaya dapat beristirahat dalam anugerah Allah. ${ }^{51}$ Hasil terbesar yang bisa diperoleh dari istirahat Sabat adalah suatu kesempatan untuk dapat mengenal hadirat Allah, tanpa harus memusingkan dengan keadaan sekeliling kita, karena sesungguhnya dalam menghadapi berbagai tragedi kita tidak bergantung pada kekuatan sendiri, melainkan spiritual rest itulah yang memberikan kebebasan untuk menerima fakta bahwa kebahagian manusia tidak stabil dan untuk itu, kita memerlukan anugerah untuk dapat melaluinya. ${ }^{52}$

Murray sependapat dengan Calvin, bahkan melangkah lebih jauh dalam penerapan Sabat. Bagi Murray spiritual rest Sabat tidak boleh dimaknai dengan tidak melakukan kegiatan. Walau rest itu berarti berhenti dari pekerjaan yang biasa dilakukan selama enam hari, namun juga harus ada pengertian rest to dan rest in the Lord. Hal ini berarti ketika Sabat maka kita bukan saja beristirahat dari bekerja, tetapi juga beristirahat di dalam beribadah secara khusus kepada Tuhan. Ada kelepasan dari segala pekerjaan selama enam hari, tetapi juga ada kelepasan untuk merenungkan akan kemuliaan Allah. Berhentinya segala pekerjaan selama seminggu itu

\footnotetext{
adalah kata "instruksi".

51 Dawn, Keeping the Sabbath Wholly, 57.

52 Ibid., 61.
} 
harus memiliki sumber dan dasar di dalam ketaatan akan Allah, dan ucapan syukur sebagai motivasinya. Dengan begitu, ibadah merupakan "pekerjaan" yang khusus dalam Sabat. ${ }^{53}$

\section{Sabat sebagai Sakramen}

Dalam tafsiran kitab Yehezkiel 20:12-20, Calvin memberikan perspektif yang berbeda terhadap Sabat. Di sini Calvin menguraikan tentang Sabat Yahudi sebagai sakramen. ${ }^{54}$ Kata "sakramen" sendiri tidak terdapat dalam kitab suci. Kata ini berasal dari terjemahan bahasa Latin yang diambil dari kata dalam bahasa Yunani "mysterion" atau "mystery" seperti yang terdapat dalam Perjanjian Baru.55 Agar pengertian sakramen ini tidak membingungkan dari dua sakramen yang diakui oleh Calvin dan para reformator yaitu perjamuan kudus dan baptisan kudus, ${ }^{56}$ maka Calvin menggunakan sakramen dengan pemahaman yang lebih luas, seperti yang disampaikannya dalam Institutes: “The term "sacrament,"... embraces generally all those signs which God has ever enjoined upon men to render them more certain and confident of the truth of his promises." 57 Hal ini selaras dengan ajaran Agustinus bahwa sakramen adalah sebagai suatu bentuk yang kelihatan

\footnotetext{
53 Murray, Collected Writings, 210.

54 Calvin, Institutes, 4.14.1. Calvin mendefinisikan sakramen sebagai: "an outward sign by which the Lord seals on our consciences the promises of his good will toward us in order to sustain the weakness of our faith; and we in turn attest our piety toward him in the presence of the Lord and of his angels and before men."

55 Gordon J. Spykman, Reformational Theology, A new Paradigm for Doing Dogmatics (Grand Rapids: Eerdmanns, 1992), 458.

56 Calvin, Institutes, 4.14.20, "... two sacraments were instituted which the Christian church now uses, Baptism and the Lord's Supper."

57 Ibid., 4.14.18.
} 
dari suatu anugerah yang tidak kelihatan. Sabat Yahudi sebagai sakramen, dipahami sebagai alat anugerah "means of grace," 58 dan suatu stimulant demi pertumbuhan rohani. Khusus dalam tafsirannya di kitab Yehezkiel 20:20, Calvin menambahkan pemahaman Sabat, bukan hanya sebagai alat anugerah, melainkan juga sebagai sebuah sakramen dari regenerasi. ${ }^{59}$

Jika penulis memperhatikan apa yang dikatakan Gordon J. Spykman tentang regenerasi, maka ada hubungan korelatif antara Sabat dan sakramen, seperti yang dipahami Calvin. Sabat sebagai alat "means of grace" yang membawa seorang Kristen kepada pembenaran, pertobatan dan penyucian. ${ }^{60}$ Louis Berkhof mengatakan bahwa regenerasi merupakan perbuatan Allah yang diterima oleh orang berdosa, dengan kehidupan dan "kelahiran baru". Berkhof menyimpulkan regenerasi sebagai:

The word "regeneration" is generally used in a more restricted sense, as a designation of that divine act by which the sinner is endowed with new spiritual life, and by which that new life is first called into action. So conceived, it includes both the "begetting again" and the "new birth." 61

58 Louis Berkhof, Systematic Theology (Grand Rapids: Eerdmans,1941), 604. Istilah "means of grace" memang tidak terdapat dalam Kitab Suci, namun merupakan penggunaan istilah yang tepat, sebagai suatu alat yang terindikasi di dalam alkitab. Berkhof menjelaskan empat karakteristik dari pengertian sakramen sebagai "alat anugerah", yakni: Pertama, sakramen adalah alat, bukan anugerah yang "common" tetapi "special". Kedua, sakramen adalah baik dalam dirinya sendiri, bukan karena berkaitan dengan hal di luar dirinya. Ketiga, sakramen adalah alat dari anugerah Allah yang berkelanjutan. Keempat, sakramen adalah official means dari gereja Yesus Kristus. Bandingkan Calvin, Institutes, 4.14.1 “...it does not differ in meaning from that of Augustine, who teaches that a sacrament is "a visible sign of a sacred thing," or "a visible form of an invisible grace."

59 Calvin, Institutes, 3.3.3-10.

60 Spykman, Reformational Theology, 487.

61 Louis Berkhof, Systematic Theology (Grand Rapids: Eerdmans, 1941), 467. 
Witsius (1636-1708) walaupun tidak secara langsung mendukung Calvin, berpendapat bahwa tidak salah menyebutkan Sabat sebagai sakramen atau sacred sign or seal dari suatu janji keselamatan yang dibuat oleh Allah bagi Adam, ${ }^{62}$ dan Sabat sebagai simbol sekaligus juga dipandang sebagai sakramen dari suatu perjanjian kerja.

God also granted to man such symbols under the Covenant of Works; concerning which we are now to speak, that nothing maybe wanting in this treatise, and, if I mistake not, were four in all, which I reckon up in this order: 1. Paradise 2. The Tree of Life 3.The Tree of Knowledge of God and Evil 4.The Sabbath. In speaking of each of these I shall distinctly shew first, what good they signified and sealed to man, with respect to God. Secondly, what duty and obligation they reminded him of.$^{63}$

Pemahaman Sabat sebagai sakramen ini tidak diterima oleh Gaffin. Ia memberikan kritik cukup tajam terhadap pernyataan Calvin ini. Semestinya Calvin tidak bisa mengatakan bahwa Sabat adalah sebuah sakramen, adapun keberatan Gaffin: Pertama, dapatkah Sabat Yahudi yang hanya ada di dalam kitab Perjanjian Lama khususnya Yehezkiel 20:12-20 itu Calvin sebut sebagai sebuah sakramen? Kedua, jika menerima Sabat sebagai sebuah sakramen maka Sabat adalah sakramen yang ketiga, setelah sakramen baptisan dan perjamuan kudus. Bagi Gaffin, ini akan membingungkan

62 Witsius, The Economy of the Covenants, 122. Bagi Witsius, tidaklah bijak mempersoalkan istilah kata "sakramen", yang tidak terdapat dalam Kitab Suci. Namun ada makna yang mistis, dan pengharapan akan Sabat sebagai istirahat yang kekal dan sukacita, seperti yang tertulis dalam Ibrani 4:10. Bdk. J.I. Packer dalam pendahuluan buku karya Witsius ini berpendapat: “He was a masterful Dutch Reformed theologian, learned, wise, minghty in the scripture, practical and "experemintal". On paper he was calm, judicious, systematic, clear and free from personal oddities and animosities. He was a man whose work stands comparison for substance and thrust with that of his younger British contemporary John Owen."

63 Ibid., 105. 
ketetapan para reformator bahwa hanya ada dua buah sakramen saja. ${ }^{64}$ Menurut penulis, dalam hal ini Calvin memang menggunakan kata sakramen dengan pengertian yang luas.

It now follows, as I lately touch on it, that the Sabbath was a sacrament, since it was a visible figure of an invisible grace. And this also is expressed with sufficient clearness by the Prophet, when he says, the Sabbath was given for a sign. ${ }^{65}$

\section{Konsep Sabat dalam Perjanjian Baru}

\section{Sabat dan Anak Manusia}

Penulis mengambil pembahasan tentang tema ini, dari tafsiran Calvin terhadap teks Matius 12:1-8; Markus 2:23-27; Lukas 6:1-5. Di awal tafsirannya ini, Calvin dengan keras mengatakan bahwa perayaan Sabat pada era Perjanjian Baru masih tetap sebatas pada ibadah yang bersifat kedagingan "carnal worship" dan kemunafikan. Calvin mencatat lima argumentasi keberatan dari Yesus, yaitu:

Pertama, ${ }^{66}$ Yesus memberi contoh tindakan Daud ketika lapar, ia memakan roti sajian yang kudus, karena unsur necessity. Dengan memberi contoh Daud, tentunya Yesus memandang bahwa tindakan para muridNya adalah tidak melanggar hukum Sabat. Murray memasukkan kegiatan yang para murid lakukan ke dalam kategori "pekerjaan keharusan."

Kedua, berkaitan dengan pekerjaan dalam ibadah di bait Allah, seperti sunat, dan pemotongan hewan korban secara hukum diperbolehkan,

\footnotetext{
64 Gaffin, Calvin and the Sabbath, 93.

65 John Calvin, Commentaries on the Prophet Ezekiel, terj. Thomas Myers, M.A. (Grand Rapids: Baker, 1993), 311-312.

66 John Calvin, Commentary on a Harmony of Evangelists, terj. William Pringle (Grand Rapids: Baker, 1993), 46-51.
} 
karena termasuk "pekerjaan kesalehan." Dalam hal ini para murid bersama Kristus sedang mencari "bait Allah yang benar dan rohani."

Ketiga, Kristus menegur orang Farisi ${ }^{67}$ yang tidak memahami fungsi seremonial dari suatu kegiatan dengan benar. Calvin menjelaskan bahwa berbagai kegiatan yang bersifat seremonial dalam hukum Sabat sesungguhnya hanya merupakan alat bagi suatu penyembahan dan pelayanan kepada Allah, dan yang merupakan pelayanan yang tertinggi adalah kasih dan kebaikan kepada sesama.

Keempat, "For the Son of Man is Lord of the Sabbath" menunjukkan bahwa Kristus memiliki otoritas untuk membebaskan para murid dari melaksanakan kewajiban Sabat, jika Yesus mempertimbangkan bahwa kegiatan itu merupakan suatu keharusan.

Kelima, "The Sabbath was made for man". Yesus kembali menjelaskan kepada orang Farisi bahwa Sabat dibuat adalah untuk kebaikan manusia dan bukan untuk mendatangkan kehancuran.

Murray mengingatkan bahwa untuk membaca tafsiran Calvin tersebut jangan melupakan konteks, "and the context always determines the meaning of what is said." 68 Pada saat itu Yesus sedang menyampaikan tiga hal yang penting. Pertama, mengenai pelaksanaan akan berbagai peraturan

67 Merryl C.Tenney, New Testament Survey (Grand Rapids: Eerdmans, 1961), 110. Dijelaskan bahwa kaum Farisi adalah sekte yang paling banyak pengikutnya dan paling berpengaruh dalam masa Perjanjian Baru. Nama mereka diambil dari kata kerja parash, yang berarti "memisahkan". Mereka berasal dari suatu kelompok yang terpisah pada zaman sesudah Makabe, pada tahun 135 SM. Teologinya didasarkan atas seluruh hukum dalam Perjanjian Lama, yang meliputi hukum Musa (Taurat), kitab para Nabi, dan tulisan para imam. Mereka memelihara hukum Sabat dengan sangat ketat, hingga menyembuhkan orang sakit atau sekedar memetik bulir gandum sambil berjalan pun tidak mereka perkenankan.

68 Murray, Collected Writings, 213. 
Sabat. Perbuatan-perbuatan dikategorikan ke dalam: piety (pekerjaan yang berkaitan dengan ibadah), necessity (pekerjaan keharusan), dan mercy works (perbuatan kasih). Ketaatan kita pada perintah Sabat harus berdasarkan pada hukum Allah yang agung, yang membebaskan, yang terkandung dalam Firman. ${ }^{69}$ Kedua, jabatan sebagai Tuhan atas hari Sabat, sesungguhnya menunjukkan identitas dirinya sebagai Mesias, maka keilahianNya di sini bersifat penebusan sebagai perantara/ Mediator dan Penyelamat/ Savior. KeilahianNya dibuktikan dengan otoritasnya atas sorga dan bumi ini..$^{70}$ Ketiga, Yesus juga menegaskan keilahianNya atas penetapan Sabat sebagai perintah keempat dalam Dekalog. Dan tidak ada sedikitpun pemberitahuanNya untuk pembatalan Sabat, yang ada adalah Yesus mencela atas penyimpangan Sabat yang telah dilakukan oleh orang Farisi. Keempat, ini adalah waktu yang tepat bagi sebuah pemahaman yang baru akan keilahian Yesus atas Sabat melalui penebusanNya atas hukum keempat. Melalui perkataanNya maka Ia memeteraikannya bagi kita: “Anak manusia adalah Tuhan atas hari Sabat."71

\section{Distingsi Sabat dan Hari Tuhan ${ }^{72}$}

Di sini Calvin memberikan tafsiran yang menyatakan bahwa Hari Tuhan/ "the Lord's day" adalah merupakan kelanjutan dari Sabat Yahudi yang ada dalam Perjanjian Lama. Namun demikian kita harus

69 Ibid.

70 Yoh. 3:35; Mat. 28:18.

71 Murray, Collected Writings, 223.

72 Luk. 4:16; I Kor. 16:2; Gal. 4:9-10; Kol. 2:16-17. 
memperhatikan beberapa penjelasan Calvin sebagai berikut: Pertama, Calvin menyetujui bahwa hari Tuhan adalah sebagai alat untuk memenuhi kewajiban hukum keempat bagi orang Kristen. Calvin menjelaskan bahwa dalam Injil Lukas, Yesus memberikan teladan untuk tetap memelihara Sabat yaitu dengan pergi ke Sinagoge, ${ }^{73}$ dengan cara membaca Kitab Suci, beribadah dan merenungkan Firman. Demikian pula dengan Paulus yang melanjutkan Sabat Yahudi bagi orang Kristen, dengan cara berkumpul bersama untuk mendengarkan Firman, berdoa bersama, dan melatih kerohanian. Calvin menyimpulkan bahwa untuk tujuan inilah Sabat Yahudi dilanjutkan dengan hari Tuhan. "It was for this purpose that the Jewish Sabbath was succeeded by the Lord's Day."74 Pelaksanaan Sabat hendaknya mengikuti petunjuk, seperti yang diberikan dalam Perjanjian Baru tentang gereja yang berkumpul bersama demi suatu keteraturan. ${ }^{75}$ Cara terbaik bagi orang Kristen untuk menjalankan Sabat adalah menyisihkan waktu satu hari dalam seminggu untuk beribadah padaNya, dan hari Minggu/ "the Lord's day" adalah sesuai dengan penggantian yang dilakukan oleh gereja mulamula yang menggantikan Sabat Yahudi di hari ketujuh dengan hari pertama minggu itu atau sesuai dengan hari kebangkitan Kristus.

\footnotetext{
73 Gaffin, Calvin and the Sabbath, 98. Bdk. Tenney, New Testament Survey, 93. Menjelaskan bahwa: Sinagoge mempunyai peranan besar dalam pertumbuhan dan kelestarianYudaisme. Sinagoge berfungsi sebagai balai sosial di mana penduduk Yahudi di kota yang bersangkutan berkumpul setiap Minggu untuk berjumpa satu dengan lainnya. Sinagoge juga menjadi sarana pendidikan untuk tetap memelihara hukum Taurat dan mendidik anak-anak mereka dalam iman/ kepercayaan nenek moyangnya. Sinagoge menggantikan Bait Allah yang sulit dijangkau karena jarak yang jauh dan karena ketiadaan biaya.

74 Calvin, Harmony of Evangelists, 227.

75 I Kor. 14:40.
} 
Kedua, Tafsiran Calvin dari surat Galatia menjadi salah satu bukti teks, bahwa tidak lagi perlu pelaksanaan aspek seremonial hukum keempat, dan sebagai lambang, fungsinya sudah dihapuskan. Jadi tidak ada lagi kewajiban untuk memelihara hari, bulan, atau tahun-tahun tertentu sebagai waktu yang dikhususkan.

Ketiga, Calvin menekankan bahwa memperlakukan atau membedakan hari-hari tertentu termasuk hari Sabat sebagai hari yang suci an sich adalah tidak benar. Tidak ada hari tertentu yang bisa dibedakan menjadi hari yang lebih kudus dibandingkan dengan hari-hari lainnya. Pernyataan tegas ini jelas dalam tafsiran Calvin yang mengatakan:

When certain days are represented as holy in themselves, when one day is distinguished from another on religious grounds, when holy days are reckoned a part of divine worship, then days are improperly observed. The Jewish Sabbath, new moons, and other festivals, were earnestly pressed by the false apostles, because they had been appointed by the law. ${ }^{76}$

Tampak jelas bahwa Calvin menentang sikap dari Roma Katolik yang menyalahgunakan hari-hari tertentu sebagai hari-hari yang paling kudus.

The papist must therefore be held equally censurable with the false apostle; and with this additional aggravation, that while the former propose to keep those days which had been appointed by the law of God, the latter enjoin days, rashly stamped with their own seal, to be observed as most holy. ${ }^{77}$

Surat Kolose 2:16-17, menjadi suatu teks yang begitu penting dibanding teks lainnya, dalam hal memberikan dukungan bukti teks atas pendirian

\footnotetext{
76 John Calvin, Commentaries on The Epistles of Paul to the Galatians and Ephesians, terj. Rev. William Pringle (Grand Rapids: Baker, 1993), 124.

77 Calvin, Commentaries the Galatians and Ephesians, 125.
} 
Calvin tentang dihapuskannya karakter dari simbol Sabat Yahudi, dan kesucian hari tertentu, yang telah lenyap seiring dengan kedatangan Kristus. ${ }^{78}$

Keempat, Calvin menjelaskan bahwa ada perbedaan antara Sabat Yahudi dengan perayaan akan hari Tuhan bagi orang Kristen. Orang Kristen merayakan Sabat pada hari Tuhan "the Lord's day" untuk sebuah remedy (perbaikan), demi tercapainya sebuah keteraturan dalam gereja dan bukan perayaan yang bersifat seremonial seperti Sabat Yahudi. Perubahan hari dari hari ketujuh ke hari pertama yang dikenal sebagai hari Tuhan, bukanlah dari otoritas Ilahi. Prinsip Calvin, selama pilihan hari untuk beribadah itu tidak disertai dengan penentuan hari tertentu yang bersifat takhayul, maka bagi Calvin dapat diterima. Hal ini akan semakin jelas bila memperhatikan kalimat-kalimat Calvin berikut ini:

Nor do I cling to the number "seven" so as to bind the church in subjection to it. And I shall not condemn churches that have other solemn days for their meeting, provided there be no superstition. This will be so if they have regard solely to the maintenance of discipline and good order. ${ }^{79}$

Kelima, Calvin menjawab secara apologetik permasalahan Sabat dengan menempatkan dua kutub ekstrem, yaitu posisi "restless spirits" yang merefleksikan kelompok Anabaptis, dan "false prophets" yang merefleksikan pandangan Roma Katolik pada waktu itu. ${ }^{80}$

\footnotetext{
78 Gaffin, Calvin and the Sabbath,107.

79 Calvin, Institutes, 2.8.34.

80 Gaffin, Calvin and the Sabbath, 44. Seperti yang dikatakan Gaffin, Anabaptis menolak bahwa Alkitab mengajarkan istirahat Sabat, dan bahkan tetap bekerja pada hari Minggu seperti hari lainnya. Sebaliknya Roma Katolik merayakan hari-hari tertentu secara legalis. Bdk. Gaffin, Calvin and the Sabbath, 25.
} 


\section{Sabat Eskatologis/ abadi}

Calvin membandingkan antara Sabat Yahudi yang masuk tanah Kanaan di bawah kepemimpinan Yosua, dengan Sabat Kristen yang menantikan kebahagiaan yang tertinggi di dalam kekekalan, di bawah kepemimpinan Yesus, di mana manusia akan dipersatukan dan menjadi seperti Allah. ${ }^{81}$ Sabat dan kelimpahan yang dinikmati oleh bangsa Israel di Kanaan merupakan simbol untuk mengarahkan Israel kepada spiritual rest yang sesungguhnya. Namun bagi orang Kristen Sabat bukan merupakan simbol lagi seperti Israel. Hal ini tampak jelas dengan uraian Calvin sebagai berikut:

And we may hence easily learn the difference between us and them; for though the same end is design for both, yet they had, as added to them, external type to guide them; not so have we, nor have we indeed any need of them, for the naked truth itself is set before our eyes. ${ }^{82}$

Penulis menggunakan terminologi Sabat eskatologis untuk menunjuk kepada Sabat yang ditulis dalam Ibrani 4:7-10. Sebagai orang percaya, sudah dapat menikmati rest dalam dunia ini, namun rest yang belum sempurna, maka harus tetap berjuang untuk rest yang kekal itu, yang di dalam Institutes digunakan istilah "Sabbath in the Last Day" dan Calvin juga mengutip Yesaya 66:23 "Bulan berganti bulan, dan Sabat berganti Sabat,..." 83

81 John Calvin, Commentaries on the Epistle of Paul to Hebrews (Grand Rapids: Baker, 1993), 98.

"This is a definition of that perpetual Sabbath in which there is a the highest felicity, when there will be a likeness between men and God, to whom they will be united."

82 Ibid., 97-98.

83 Calvin, Institutes, 2.8.30. "the Lord thus indicated that the Sabbath would never be perfected until the Last Day should come. For we here begin our blessed rest in him; daily we make fresh progress in it. But because there is still a continual warfare with the flesh, it will not be consummated until Isaiah's saying is fulfilled about "new moon following new moon and Sabbath following Sabbath." 
Selain itu Sabat eskatologis disebut pula sebagai "perpetual sabbath" yang didefinisikan Calvin sebagai kebahagiaan yang tertinggi dimana akan ada keserupaan antara manusia dengan Allah karena manusia dipersatukan dengan Allah. ${ }^{84}$

Namun bagi Barth penekanan terhadap Sabat eskatologis yang dikemukakan Calvin tidak memiliki dasar yang kuat, ${ }^{85}$ oleh karena itu Barth lebih melihat Sabat sebagai hari khusus untuk dapat berkat/ keuntungan melalui perayaannya. Keuntungan Sabat bisa berupa aktif dalam "divine service" dengan mendengarkan Firman, mendapatkan penyegaran fisik, dan hari untuk menikmati berbagai persekutuan sosial dengan sesama. ${ }^{86}$ Dengan cara beriman kepada Allah meninggalkan kepentingan diri, pikiran, materi, dan segala kesuksesan demi merayakan aktifitas dan non aktifitas di hari Sabat berbeda dengan hari-hari lainnya. ${ }^{87}$

Witsius lebih sependapat dengan Calvin, dengan mengatakan bahwa Sabat memiliki arti yang "mistis"dan berkaitan dengan istirahat yang kekal dan bahagia, sehingga tidak keliru jika dikatakan bahwa ada hubungan analogi antara Sabat dan eternal rest. 88 Dengan memberikan dasar dari Kitab Suci, Witsius berkata:

We have Paul's authority to assert that the Sabbath had some mystical meaning, and respected an eternal and happy rest, Heb 4:10. And this is justly supposed by the

\footnotetext{
84 Calvin, Commentaries on Hebrew, 98.

85 Barth, Church Dogmatics, 57.

86 Ibid., 69.

87 Ibid., 59.

88 Witsius, The Economy of the Covenants, 123.
} 
apostle, as a thing wellknown to the Hebrews, and which is a corner stone or fundamental point with their doctor. ${ }^{89}$

Murray memberikan konklusi yang senada dengan Calvin, dengan mengatakan bahwa pelaksanaan Sabat jangan hanya berhenti pada sebatas peringatan akan selesainya penciptaan atau penebusan saja. Namun ada janji dan antisipasi akan istirahat Sabat bagi umat Allah, yaitu "grand final to the whole of history", suatu istirahat Sabat yang merupakan janji lanjutan dari keseluruhan sejarah atas pekerjaan yang pernah ada, sebagaimana tertulis dalam 2 Petrus 3:13 dan Ibrani 4:9, yakni adanya langit dan bumi yang baru yang terdapat Sabat bagi umat Allah. ${ }^{90}$

Senada dengan Calvin, Dawn juga mengatakan bahwa memelihara Sabat sebenarnya mengajarkan kepada kita kebenaran ganda, bukan hanya aspek temporal melainkan juga kekekalan. Perayaan Sabat mingguan menolong kita agar lebih menyadari akan kehadiran Allah itu bersifat kekal, dan sebaliknya ketika kita melewati hari Minggu dan memasuki hari Senin, juga mengingatkan kita bahwa perayaan Sabat begitu singkat, dan hal ini pun akan mengantisipasi kita terhadap perayaan yang kekal yang akan kita nikmati di hadapan Allah. ${ }^{91}$

89 Ibid.,122.

90 Murray, Collected Writings, 216. "The weekly Sabbath in the divinely established sequences of temporal history is the constant reminder to us of the beginning and the end. And for the people of God it is the foretaste of that eternal rest which was secure by redemption once for all accomplished and will be dispensed in redemtion consummated. The perpetual relevance of the weekly Sabbath resides in the devine plan of history and of destiny, and with its perpetual relevance goes its perpetual obligation."

91 Dawn, Keep the Sabbat Wholly, 153. 


\section{Kesimpulan}

Dengan memperhatikan deskripsi kritis di atas, maka penulis menarik beberapa poin penting dari konsep Sabat Calvin sebagai berikut:

Pertama, Calvin tidak ingin terjebak dalam pandangan yang tidak memiliki dasar Alkitab yang kuat tentang Sabat. Khususnya menanggapi penetapan hari Sabat yang jatuh pada hari ketujuh atau hari pertama. Baik di awal pembahasan hukum keempat di Institutes, ${ }^{92}$ dalam tafsirannya di kitab Perjanjian Lama maupun Perjanjian Baru, dan di tulisan-tulisan lainnya, Calvin mengatakan hari Sabat Kristen jatuh pada "a stated day" atau "a day of rest." Calvin mengambil "middle way," dalam arti tidak terjebak dalam dua pandangan ekstrim yang ada, baik dari kelompok Anabaptis, maupun Roma Katolik dan tetap konsisten dalam berpegang teguh pada kebenaran Kitab Suci. Selain itu harus selalu diingat bahwa Calvin adalah "anak pada zamannya," di mana berbagai pemikiran teologisnya juga harus dilihat dari konteks pergumulan yang tengah dihadapinya, khususnya di dalam menghadapi berbagai ajaran yang menyimpang dari Alkitab dan tidak mungkin menjawab seluruh tuntutan zaman yang berkaitan dengan pelaksanaan Sabat.93 Kedua, "spiritual rest" menjadi penekanan utama Calvin dalam menggarisbawahi konsep Sabat. Spiritual rest diartikannya secara luas. Mulai rest dari kegiatan fisik dalam arti berhenti dari berbagai kegiatan/ pekerjaan yang dilakukan selama enam hari, sampai kepada rest secara rohani yaitu berhenti dari perbuatan dosa. Dengan dua pengertian rest tersebut, maka Allah sanggup menguatkan dan menyegarkan jasmani

\footnotetext{
92 Calvin, Institutes, 2.8.28.

93 Hall, Tributes to John Calvin, 218.
} 
serta rohani orang Kristen yang melaksanakan Sabat, agar dapat hidup sesuai dengan kehendak Allah yang terdapat di dalam persatuannya dengan Kristus.

Ketiga, sejak kedatangan Kristus maka Sabat Yahudi sebagai simbol dan sakramen/ tanda yang terdapat dalam Perjanjian Lama sudah digenapi, karena Sabat Yahudi adalah bayang-bayang dan spiritual rest kini menjadi suatu realitas. ${ }^{94}$ Penggenapan Sabat Yahudi sebagai simbol dan sakramen, bukan semata-mata akibat kejatuhan dalam penciptaan, melainkan adanya teladan ilahi dari sejak penciptaan itu sendiri. Dengan demikian walaupun Sabat Yahudi telah digenapi oleh Kristus, namun Sabat Kristen tetap berlanjut. Keempat, sehubungan dengan poin ketiga di atas, maka pelaksanaan Sabat Kristen bisa saja dilakukan pada hari selain hari Minggu (the Lord's day), selama tidak menjadi hari takhayul dengan mensakralkan hari tertentu, dan demi keteraturan pelaksanaan ibadah bersama gereja. Pelaksanaan Sabat pada hari Minggu, sesuai dengan kebiasaan yang telah dilakukan oleh gereja mula-mula. ${ }^{95}$

Kelima, sementara masih ada dalam dunia ini, maka pelaksanaan Sabat tidak bisa hanya dibatasi satu hari dalam seminggu saja, melainkan dengan pergumulan setiap hari, agar suatu hari dapat menikmati spiritual rest yang kekal di bumi dan langit yang baru itu di dalam Sabat yang kekal.

\footnotetext{
94 Gaffin, Calvin and the Sabbath, 142.

95 Ayat yang sering dijadikan dasar bagi mereka yang memegang hari Minggu sebagai the Lord's day atau sebagai sabat Kristen adalah Kisah Rasul 20:7 dan I Korintus 16:2.
} 